\title{
OPTIMIZATION OF SOLVENT MIXTURES FOR EXTRACTION FROM BARK OF Schinus terebinthifolius BY A STATISTICAL MIXTURE-DESIGN TECHNIQUE AND DEVELOPMENT OF A UV-VIS SPECTROPHOTOMETRIC METHOD FOR ANALYSIS OF TOTAL POLYPHENOLS IN THE EXTRACT
}

\author{
Maria Cristina DiCiaula ${ }^{a}$, Gisely C. Lopes ${ }^{a}$, Ieda S. Scarminio ${ }^{\mathrm{b}}$ and João Carlos P. de Mello ${ }^{\mathrm{a}, *}$ \\ aDepartamento de Farmácia, Universidade Estadual de Maringá, 87020-900 Maringá - PR, Brasil \\ bDepartamento de Química, Universidade Estadual de Londrina, CP 6001, 86051-970 Londrina - PR, Brasil
}

Recebido em 09/05/2013; aceito em 05/08/2013; publicado na web em 30/09/2013

\begin{abstract}
A statistical mixture-design technique was used to study the effects of different solvents and their mixtures on the yield, total polyphenol content, and antioxidant capacity of the crude extracts from the bark of Schinus terebinthifolius Raddi (Anacardiaceae). The experimental results and their response-surface models showed that ternary mixtures with equal portions of all the three solvents (water, ethanol and acetone) were better than the binary mixtures in generating crude extracts with the highest yield $(22.04 \pm 0.48 \%$ ), total polyphenol content $(29.39 \pm 0.39 \%)$, and antioxidant capacity $(6.38 \pm 0.21)$. An analytical method was developed and validated for the determination of total polyphenols in the extracts. Optimal conditions for the various parameters in this analytical method, namely, the time for the chromophoric reaction to stabilize, wavelength of the absorption maxima to be monitored, the reference standard and the concentration of sodium carbonate were determined to be $5 \mathrm{~min}, 780 \mathrm{~nm}$, pyrogallol, and $14.06 \% \mathrm{w} \mathrm{v}^{-1}$, respectively. UV-Vis spectrophotometric monitoring of the reaction under these conditions proved the method to be linear, specific, precise, accurate, reproducible, robust, and easy to perform.
\end{abstract}

Keywords: Schinus terebinthifolius; simplex centroid design; UV-Vis spectroscopy validation.

\section{INTRODUCTION}

Most of the plant compounds that have been found to be medicinally useful and interesting tend to be secondary metabolites, which usually occur in low concentrations. ${ }^{1}$ Isolated yields of these metabolites are dependent on the solvents and methods of extraction. Extraction techniques to obtain valuable natural compounds from plants have been widely investigated. Although the choice of the extraction method may have a considerable effect on the quality of the extract, the nature of the solvent used for extraction provides the most obvious means of influencing the qualitative composition of the extract. However, little attention is usually paid to the selection of an appropriate solvent or a solvent system for extraction. In spite of all the extraction applications reported in the literature, few systematic studies investigate the effect of changing solvent proportions in binary and ternary mixtures. The choice of extraction solvent strongly affects the yield and the number of metabolites obtained. ${ }^{2}$ Different solvent systems have been used to extract secondary metabolites from plant materials because their extraction efficacy depends on their chemical nature. For example, ethyl alcohol extracts a large number of flavonoids, whereas terpenes can be selectively extracted at neutral $\mathrm{pH}$ with ethyl acetate or aliphatic ketones. Aqueous mixtures of ethanol, methanol, and acetone have been used to extract polyphenols from plant material, but no single solvent can extract all compounds with their different polarities. ${ }^{3}$

Schinus terebinthifolius Raddi, a medicinal plant which is known in Brazil as 'Aroeira da Praia', is distributed from northeastern to southern Brazil in coastal areas. Many studies have confirmed experimentally that this plant has antimicrobial, anti-inflammatory and antiulcerogenic properties. In folk medicine, it is also used as a febrifuge, analgesic and depurative, and to treat illnesses of the urogenital system $;{ }^{4}$ in France, it is used in cooking, and is called 'poivre rose', a type of sweet pepper. ${ }^{5}$

*e-mail: mello@uem.br
S. terebinthifolius is one of 71 medicinal plants on the National List of Medicinal Plants (RENISUS) of Interest to the National Health System in Brazil (SUS). This list was developed under a national policy, implemented by the Ministry of Health, which aims at the development of herbal medicines. The list includes native and exotic plant species that furnish medicines which are widely used by the population, and for which evidence indicates their potential use in primary health care. ${ }^{6}$

The Folin-Ciocalteu method is widely used to determine total polyphenols. In this reaction phosphotungstic acid is reduced and forms a blue phosphotungstic-phosphomolybdenum complex. The absorption maxima of these blue pigments depend on the qualitative and/or quantitative composition of phenolic mixtures as well as on the $\mathrm{pH}$ of solutions. The $\mathrm{pH}$ of the solution is usually modified by adding sodium carbonate. Cicco et al. $^{7}$ noted the widespread use of the technique and its variants, including the amounts of Folin-Ciocalteu reagents, the sequence in which the reagents are added, sodium-carbonate concentration, wavelength for monitoring, the standards used, time period, and temperature. Considering the variations in this method, the present study develops a standard procedure for the pre-analytical method and analytical validation for the determination of total polyphenols in the crude extract from the bark of S. terebinthifolius.

This study evaluates the effects of solvents and their mixtures on the yield, total polyphenol content, and antioxidant capacity of the crude extracts. Taking into account the lack of prior study of members of the genus Schinus, a simplex centroid mixture-design of three components was used for the extraction of plant material from bark of S. terebinthifolius.

\section{EXPERIMENTAL}

\section{Plant material}

The bark of S. terebinthifolius was collected in June 2011 in Caetité, state of Bahia, Brazil. A voucher specimen (\#22057) has 
been deposited in the Herbarium of the Universidade Estadual de Maringá (HUEM). The bark was dried to constant weight at room temperature and then powdered in a hammer mill (Tigre ASN-5). The samples were enclosed in cotton bags to protect them from light, insects and fungus.

\section{Chemicals}

The solvents, reagents and standard used were: ethanol (Cereálcool®, Brazil), acetone (Vetec ${ }^{\circledR}$, Brazil), Folin-Ciocalteu reagent (Dynamica®, Brazil), methanol HPLC grade (J.T. Baker, USA), anhydrous sodium carbonate (Nuclear $\AA$, Brazil), the standards pyrogallol ( $\geq 98 \%)$, and pure caffeine $(\geq 99.0 \%)$ (Sigma ${ }^{\circledR}$, USA).

\section{Mixture design and extract preparation}

Extraction solvents were mixtures of water, ethanol, and acetone, in varying proportions according to a simplex centroid design. These solvent mixtures followed the simplex centroid design for three solvents as shown in Figure 1. The three points at the vertices of the triangle correspond to extractions carried out independently using each of the pure solvents, water, ethanol, and acetone. The three midpoints of the sides of the triangle correspond to 1:1 binary mixtures of these solvents. The center point of the triangle represents a three-component mixture of equal portions. Ternary mixtures using different proportions were also investigated, and are represented in Figure 1 by the points 8, 9, and 10 . Air-dried stem bark (100.0 g) was extracted with $1000.0 \mathrm{~mL}$ of solvent for 20 min using the compositions specified in the experimental design by turbo-extraction (Skymsen®, model LS-04). Next, the crude extract was filtered and concentrated in a rotavapor under reduced pressure, and then lyophilized. A three-run replicate was performed at the center point so that the experimental error could be estimated.

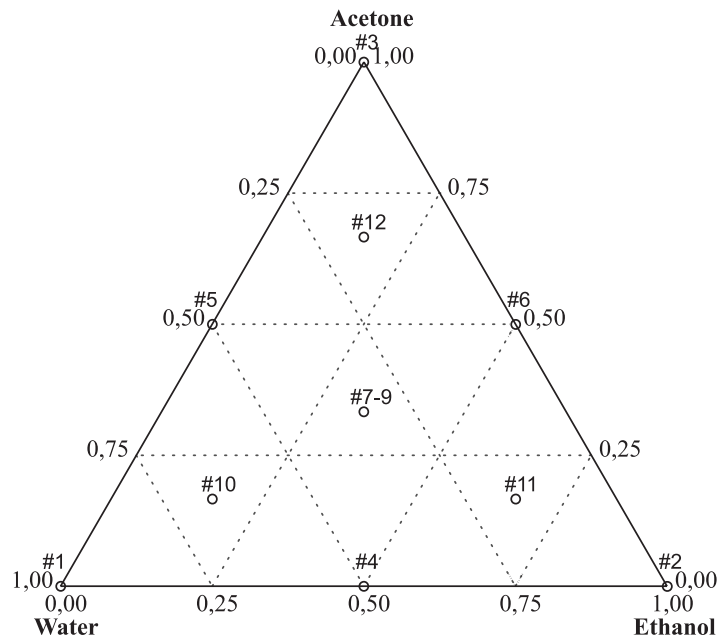

Figure 1. Simplex centroid design used to optimize the extraction. The points correspond to the mixtures in Table 1

\section{DPPH-radical-scavenging capacity}

The free-radical scavenging capacities of extracts of $S$. terebinthifolius were measured by using 2,2-diphenyl-1-picryl-hydrazyl (DPPH). ${ }^{8}$ Solutions of each crude extract (CE) and Vitamin C (ascorbic acid, Delaware, Brazil) at different concentrations $\left(1-6 \mu \mathrm{g} \mathrm{mL}^{-1}\right)$ were dissolved in $3 \mathrm{~mL}$ of methanol and then added to a methanolic solution of DPPH ( $\left.1 \mathrm{mmoL} \mathrm{L}^{-1}, 375 \mu \mathrm{L}\right)$. The absorbance of the resulting solution was read spectrophotometrically (Shimadzu UV-Vis
PC-1650, Japan) at $517 \mathrm{~nm}$. Tests were carried out in triplicate. The half maximal inhibitory constants $\left(\mathrm{IC}_{50}\right)$ were reported as the mean \pm standard deviation.

\section{Methodology standardization for the determination of total polyphenols}

To define the optimal conditions for the estimation of total polyphenols (TP) in the crude extracts of S. terebinthifolius, the following four parameters were initially evaluated: 1) reaction kinetics (0 to $40 \mathrm{~min}$ ); 2) absorption maxima in the 400 to $900 \mathrm{~nm}$ range; 3 ) concentration of the anhydrous sodium carbonate $(5.00,7.00,10.75$, and $14.06 \% \mathrm{w} \mathrm{v}^{-1}$ ), and 4) the identity of the standard (gallic acid, tannic acid, catechin, and pyrogallol at a concentration of $2 \mu \mathrm{g} \mathrm{mL}^{-1}$ ) that provides the best fit for the crude extract of S. terebinthifolius. The method described by the European Pharmacopoeia ${ }^{9}$ for the determination of TP was used as a guideline for the dilution of the $\mathrm{CE}$ and standards.

Solutions of the standards $\left(25 \mu \mathrm{g} \mathrm{mL}^{-1}\right)$ and CEs $\left(180 \mu \mathrm{g} \mathrm{mL}^{-1}\right)$ were prepared in distilled water. A $160 \mu \mathrm{L}$ aliquot of each solution was transferred to a microtube ( $2 \mathrm{~mL}$ capacity) containing distilled water $(800 \mu \mathrm{L})$ and the Folin-Ciocalteau reagent $(80 \mu \mathrm{L})$. Anhydrous sodium carbonate $\left(5.00,7.00,10.75\right.$ or $\left.14.06 \% \mathrm{w} \mathrm{v}^{-1}\right)$ and water were added to bring the volume up to $2 \mathrm{~mL}$, resulting in final concentrations of $2 \mu \mathrm{g} \mathrm{mL}-1$ for each of the standards and $14.4 \mu \mathrm{g} \mathrm{mL}^{-1}$ of CE. The absorption spectra (400-900 $\mathrm{nM}$ ) of the samples were recorded on a UV/Vis spectrophotometer at $1 \mathrm{~min}$ intervals for a period of $40 \mathrm{~min}$. Distilled water was used as the blank. To determine the best standard to characterize the CE from S. terebinthifolius, the molar absorptivity of each standard and the $\mathrm{CE}$ was calculated by the equation: $\mathrm{A}=\varepsilon$.b.c, where $\mathrm{A}=$ sample absorbance; $\varepsilon=$ molar absorptivity $\left(\mathrm{mol} \mathrm{L} \mathrm{mL}^{-1}\right)$; $\mathrm{b}=$ thickness of the cell $(\mathrm{cm}) ; \mathrm{c}=$ sample concentration $\left(\mathrm{g} 100 \mathrm{~mL}^{-1}\right)$. Tests were carried out in triplicate.

\section{Analytical method validation}

For validation of the analytical method, the guidelines established by the Brazilian National Health Surveillance Agency (ANVISA) Regulation 899/2003 ${ }^{10}$ were employed. The standardized method which used pyrogallol as the reference standard and had a reaction equilibration time of $5 \mathrm{~min}$ in a $14.06 \% \mathrm{w} \mathrm{v}^{-1}$ anhydrous sodium carbonate solution while monitoring the absorbance at $780 \mathrm{nM}$ was used to validate the method for the determination of total polyphenols. Analyses were performed in triplicate.

\section{Linearity}

The calibration curves of the pyrogallol standard ( 0.5 to $5.0 \mu \mathrm{g}$ $\left.\mathrm{mL}^{-1}\right)$ and $\mathrm{CE}$ (4.95 to $17.28 \mu \mathrm{g} \mathrm{mL}^{-1}$ ) were determined from five concentrations following the Lambert-Beer law. The slope and other statistical parameters of the calibration curves were calculated by linear regression with Statistica ${ }^{\circledR}$ (v 8.0).

\section{Limits of detection and quantitation}

The limits of detection (LOD) and quantitation (LOQ) were calculated from the relationship between the standard deviation (SD) of the calibration curve of the $\mathrm{CE}$ and the slope, using the appropriate multiplier.

\section{Precision}

Precision was evaluated at two levels: repeatability (intra-day) and intermediate (inter-day) precision, where the SD and relative standard deviation (RSD) of six replicates $\left(10.98 \mu \mathrm{g} \mathrm{mL} \mathrm{m}^{-1}\right)$ were considered. An RSD over $5 \%$ was considered unacceptable. 


\section{Accuracy}

The accuracy was evaluated based on the recovery, following the addition of $0.5 ; 1.0$ or $1.5 \mu \mathrm{g} \mathrm{mL} \mathrm{m}^{-1}$ of pyrogallol to the linearity solution. To determine the recovery, the values determined from the calibration curve of the standard and the linearity of the $\mathrm{CE}$ were used as the expected absorbance.

\section{Specificity}

Specificity was tested by adding $40 \mu \mathrm{L}$ aliquots of pyrogallol solution $\left(25 \mu \mathrm{g} \mathrm{mL}^{-1}\right)$ to the solutions of $\mathrm{CE}$ at five different concentrations in the linear range resulting in a final concentration of 0.5 $\mu \mathrm{g} \mathrm{mL} \mathrm{L}^{-1}$ pyrogallol. These measurements were done in triplicate. The curve generated was analyzed and compared with the curve obtained in the linearity test. The acceptance criterion for the specificity of the method was to obtain parallel curves and the same slope.

\section{Selectivity}

The selectivity of the method was tested by measuring the absorbance after adding a $40 \mu \mathrm{L}$ aliquot of a standard solution of caffeine ( $25 \mu \mathrm{g} \mathrm{mL}^{-1}$ ), which is the reference substance for methylxanthines, to the solution of the $\mathrm{CE}\left(10.98 \mu \mathrm{g} \mathrm{mL} \mathrm{m}^{-1}\right)$ of $S$. terebinthifolius resulting in a final caffeine concentration of $0.5 \mu \mathrm{g} \mathrm{mL}^{-1}$. These measurements were done in triplicate. The method was considered to be selective for polyphenols when there was no significant increase in absorbance.

\section{Robustness}

Robustness was evaluated by determining the stability of the stock solution of the CE of S. terebinthifolius in natural light for $90 \mathrm{~min}$, as the preparation for the test was done without protection from light. The samples were prepared in triplicate and the results were compared with the absorbance obtained in the test of linearity.

\section{Statistical analyses}

The statistical analyses were performed using Statistica ${ }^{\circledR}$ (v 8.0, StatSoft ${ }^{\circledR}$, Inc.). Results were expressed as mean \pm SD [RSD (\%)] and were analyzed using ANOVA. Significant differences were determined by Tukey's test, with $p<0.05$ as the significance criterion. Tests for linear correlation and residual analysis were performed by simple linear regression, and the residual " $r$ " was set as equal to or greater than 0.99 .

\section{RESULTS AND DISCUSSION}

Table 1 shows the effects of the solvent compositions on the yield of CE of the bark of S. terebinthifolius. Comparing the averages of the CE yields showed the following trend: yield of CE from pure solvents $(14.22 \pm 3.06 \%)<$ solvent mixtures $(20.25 \pm 2.44 \%)<$ ternary solvent mixtures $(22.39 \pm 2.65 \%)$ (Figure $2(\mathrm{~A}))$. For the yields of $\mathrm{CE}$ from pure solvents, acetone gave the lowest yield while water gave the highest yield with ethanol generating intermediate yields. Maximum yields of CE were obtained with ternary solvent mixtures which were followed by yields from the water-ethanol binary mixture. Extraction with water resulted in the lowest polyphenol content in the CE, whereas maximum polyphenol content was obtained with the ternary solvent mixtures. A lower value of $\mathrm{IC}_{50}$ indicates a higher antioxidant activity. Higher antioxidant capacities $(6.18 \pm 0.24)$ in CEs were obtained with the binary solvent mixtures (water:acetone, $\left.1: 1 \mathrm{v} \mathrm{v}^{-1}\right)$. On the other hand, although independent use of ethanol gave lower yields, the extract showed high antioxidant capacity and polyphenol content. Response surfaces were determined for the yield, total polyphenol content, and antioxidant capacity as a function of the extraction solvent compositions.

The quadratic model for yield showed a value of $\mathrm{R}^{2}=0.90$, and there was no lack of fit at the $95 \%$ confidence level. The model is given by (1) and is shown in Figure 2 (A):

$$
\begin{aligned}
\text { yield }= & 17.85 w+15.20 e+10.01 a+29.66 w e+22.59 w a+20.67 e a \\
& \pm 1.67 \pm 1.67 \pm 1.67 \pm 7.47 \quad \pm 7.47 \quad \pm 7.47(1)
\end{aligned}
$$

The response surface for yield as a function of the percentage composition of water, ethanol and acetone is shown in Figure 2 (A). The highest value on the contour graph occurred between positions 7 (equal portions of all three solvents) and 4 (w:e, 1:1).

ANOVA was applied to the linear, quadratic, and also special cubic models, and showed no significant lack of fit at the $95 \%$ confidence level for total polyphenol content. The quadratic and special cubic models showed $\mathrm{R}^{2}$ of 0.68 and 0.75 , respectively. Thus, the special cubic model is better in predicting the behavior of the mixture, although only the linear terms are significant. The special cubic model is given by (2) and is shown in Figure 2 (B):

$$
\begin{aligned}
T P= & 22.81 w+31.05 e+26.42 a \\
& \pm 2.71 \pm 2.71 \pm 2.71
\end{aligned}
$$

The dark region at number 7 indicates the best composition of the extraction solvent to obtain the total polyphenol extracts from $S$. terebinthifolius.

ANOVA was applied to the linear, quadratic, and also special cubic models, and showed no significant lack of fit at the $95 \%$

Table 1. Compositions of extraction mixtures, the yields of CE, polyphenol content in CEs and radical scavenging capacity of the CEs. $\mathrm{w}=\mathrm{water}$, $\mathrm{e}=\mathrm{ethanol}$, and $\mathrm{a}=$ acetone

\begin{tabular}{ccccc}
\hline Crude extract $(\mathrm{CE})$ & Solvent proportions & Residue Yield $(\%)$ & Polyphenol content $(\%)$ & Radical-Scavenging Capacity $\left(\mathrm{IC}_{50}\right)$ \\
\hline 1 & w $(1)$ & 16.86 & $22.58 \pm 0.74$ & $11.56 \pm 0.24$ \\
2 & e (1) & 15.86 & $31.40 \pm 0.85$ & $6.51 \pm 0.36$ \\
3 & a (1) & 9.93 & $25.11 \pm 0.96$ & $7.16 \pm 0.05$ \\
4 & w:e (1:1) & 23.71 & $32.21 \pm 1.00$ & $6.31 \pm 0.18$ \\
5 & w:a (1:1) & 18.60 & $25.78 \pm 0.46$ & $6.18 \pm 0.24$ \\
6 & e:a (1:1) & 18.45 & $25.68 \pm 0.40$ & $6.70 \pm 0.33$ \\
7.A & w:e:a (1:1:1) & $\mathbf{2 2 . 7 2}$ & $\mathbf{2 9 . 9 1} \pm \mathbf{1 . 0 5}$ & $\mathbf{6 . 6 1} \pm \mathbf{0 . 3 0}$ \\
7.B & w:e:a (1:1:1) & $\mathbf{2 1 . 7 5}$ & $\mathbf{2 8 . 9 7} \pm \mathbf{0 . 6 0}$ & $\mathbf{6 . 4 2} \pm \mathbf{0 . 1 5}$ \\
7.C & w:e:a (1:1:1) & $\mathbf{2 1 . 6 5}$ & $\mathbf{2 9 . 3 0} \pm \mathbf{0 . 4 6}$ & $\mathbf{6 . 1 1} \pm \mathbf{0 . 3 9}$ \\
8 & w:e:a (4:1:1) & 25.79 & $30.56 \pm 1.16$ & $7.99 \pm 0.37$ \\
9 & w:e:a (1:4:1) & 19.33 & $31.32 \pm 1.55$ & $6.65 \pm 0.31$ \\
10 & w:e:a (1:1:4) & 18.41 & $33.17 \pm 0.45$ & $7.69 \pm 0.18$ \\
\hline
\end{tabular}


confidence level for Radical-Scavenging Capacity (RSC). The quadratic model with $\mathrm{R}^{2}=0.90$ is given by (3) and is shown in Figure $2(\mathrm{C})$ :

$\begin{aligned} R S C= & 11.46 w+6.45 e+7.34 a-9.24 w e-10.59 w a \\ & \pm 0.59 \quad \pm 0.59 \quad \pm 0.59 \quad \pm 2.64 \quad \pm 2.64\end{aligned}$

The light-grey region shows the compositions of solvents for obtaining CEs with the highest antioxidant capacity, since the lower
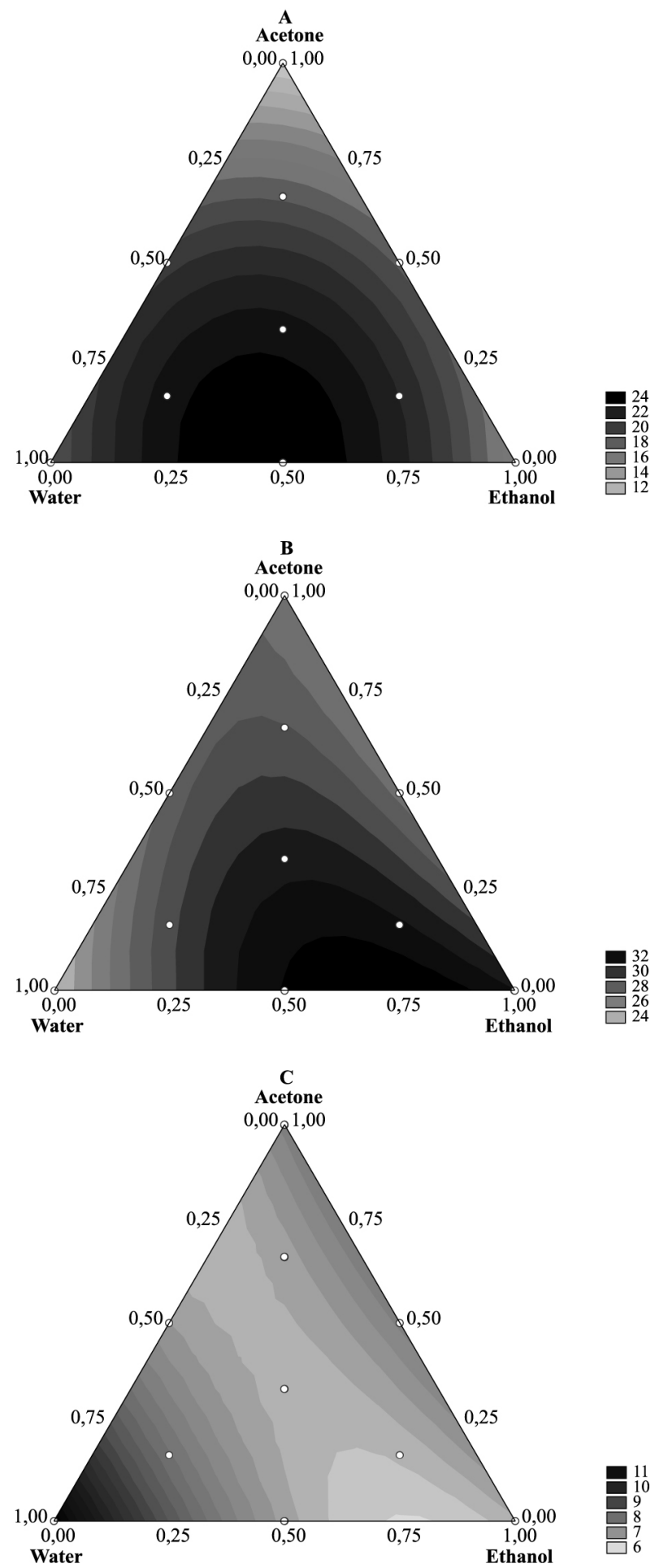

Figure 2. Response-surface contour plots of the quadratic model for (A) yield,(B) TP, and (C) $I C_{50}$ as a function of the composition of water, ethanol, and acetone the $\mathrm{IC}_{50}$ value, the higher the reducing power of the extract against the free radical DPPH.

To validate the methodology through the simplex centroid analysis, a new extract was produced and its parameters (yield, total polyphenols, and inhibitory concentration) were compared with those obtained from 10 extracts used to generate the simplex centroid.

The new extract, CE 11, was obtained with a water:ethanol (25:75, $\left.\mathrm{V} \mathrm{V}^{-1}\right)$ solution. The measured parameters were: Yield $=20.89 \%$; Total polyphenols $=32.05 \% \pm 1.38$ [4.33]; and $\mathrm{IC}_{50}=6.22 \mu \mathrm{g} \mathrm{mL}{ }^{-1} \pm 0.23$ [3.81]. The results for CE 11 were close to those obtained from other extracts in both the contour and response surfaces to polyphenols and $\mathrm{IC}_{50}$, validating the analysis by the simplex centroid method.

In the pre-analysis standardization of the technique for determination of total polyphenols, different standards $\left(2 \mu \mathrm{g} \mathrm{mL}^{-1}\right)$ and $\mathrm{CE}$ (14.4 $\mu \mathrm{g} \mathrm{mL}^{-1}$ ) were used. This is due to the wide differences among the analytical methodologies for determination of total polyphenols (TP) in S. terebinthifolius. To ensure confidence in the results, we opted to investigate all the standards. The reaction kinetics, reaction time, and stability of the peak of maximum absorption were compared. Quantities of anhydrous sodium carbonate to generate four concentrations of the reagent $\left(5.0,7.0,10.75\right.$, and $\left.14.06 \% \mathrm{~W} \mathrm{~V}^{-1}\right)$ were added to the solution containing the extract (Figure 3 ) and reference substances (Figure 4), diluted with water, followed by the addition of the Folin-Ciocalteu reagent. Next, the solutions were analyzed by a scanning UV-Vis spectrophotometer. Anhydrous sodium carbonate is a salt that turns an aqueous medium alkaline and therefore reduces polyphenols, forming tungsten blue oxide. The intensity of the blue color is proportional to the amount of polyphenols in the solution. Analyzing the results by one-way ANOVA, we observed large differences in the time required for the equilibration of the reaction for determination of TP. With $5.0 \% \mathrm{w} \mathrm{V}^{-1}$ anhydrous sodium carbonate the reaction stabilized after $25 \mathrm{~min}$, and at $7.0 \% \mathrm{w} \mathrm{v}^{-1}$ the reaction was stable after $15 \mathrm{~min}$. At a concentration of $10.75 \% \mathrm{w} \mathrm{v} \mathrm{v}^{-1}$ the reaction stabilized after $10 \mathrm{~min}$, and at $14.06 \% \mathrm{w} \mathrm{v}^{-1}$ after $5 \mathrm{~min}$, which was the shortest time. Therefore the highest concentration of anhydrous sodium carbonate studied, $14.06 \% \mathrm{w} \mathrm{V}^{-1}$, was chosen to provide the peak response to TP in CE of $S$. terebinthifolius. This optimized the assay and also increased the absorbance in this reaction. The apparatus also provided the wavelength of the absorption maxima (Figure 3 ). The wavelength corresponding to the maximum absorption was close to $780 \mathrm{~nm}$, i.e., away from those previously cited such as 691 , 715 , and $760 \mathrm{~nm} .{ }^{11,12}$ Therefore, we suggest that under our optimized conditions, the best wavelength for the determination of TP in CE of S. terebinthifolius is $780 \mathrm{~nm}$.

To determine which standard best represents the CE of S. terebinthifolius, absorbance scans (900-400 nM) of the solution containing $14.06 \% \mathrm{w} \mathrm{v}^{-1}$ anhydrous sodium carbonate were performed at $1 \mathrm{~min}$ intervals for a period of 40 mins. This concentration allowed the fastest equilibration of the reaction with pyrogallol, tannic acid, gallic acid, and catechin standards. The data in Figure 4 show that the wavelength of maximum absorption for the reference substances was also close to $780 \mathrm{~nm}$. Thus, it can be concluded that the reduction reaction of phosphotungstic acid is stable and that the increase in absorbance after the 5 min time-point does not exceed $5 \%$ of the absorbance at 0 min time-point. Furthermore, the absorbance did not decrease after $5 \mathrm{~min}$. Thus, a 5 min equilibration period was used as a cut-off time for recording the spectra, so that the CE of $S$. terebinthifolius and the standard were read at the same time. The reaction kinetics of Folin-Ciocalteu reagent with pyrogallol and CE of S. terebinthifolius showed a similar pattern. In addition, the compounds studied have different specific absorptivities (gallic acid $=1445$; tannic acid $=$ 1195; catechin $=965$ and pyrogallol $=1505$ ), showing that different polyphenols can change the color of the reaction solution per unit 

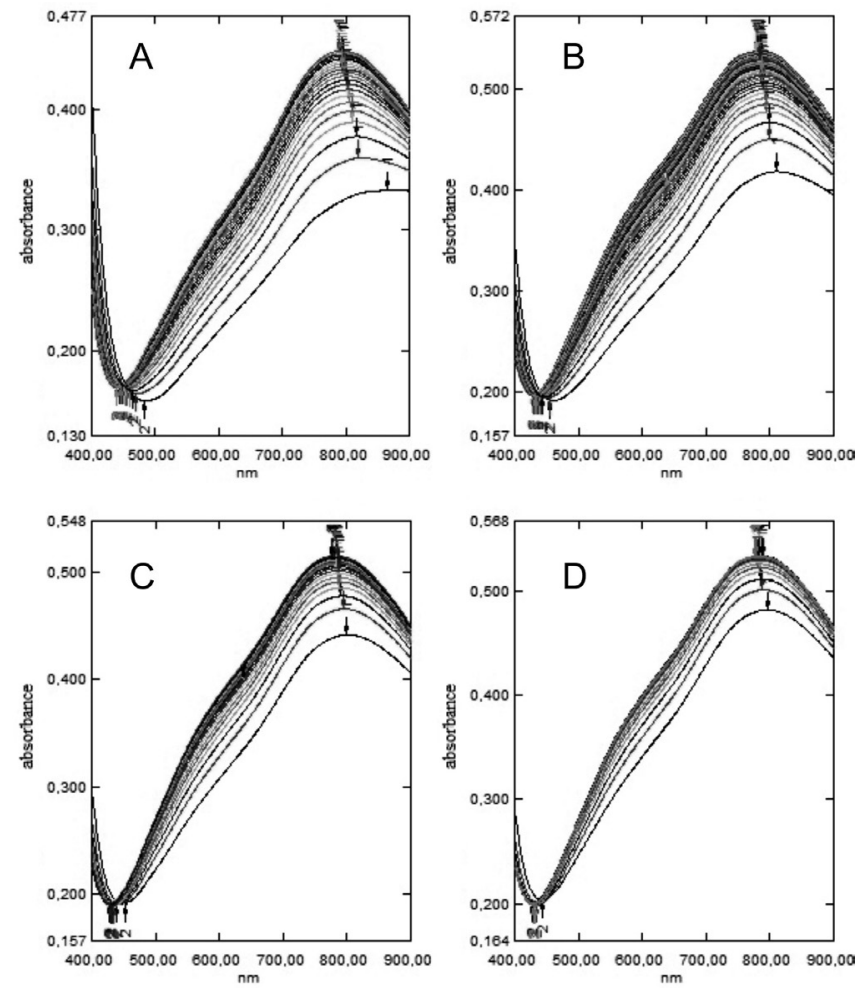

Figure 3. Absorption spectra $(900-400 \mathrm{~nm})$ for the solutions of CE at different concentrations of sodium carbonate $\left(w v^{-1}\right)$. (A) $5.0 \%$, (B) $7.0 \%,(C) 10.75 \%$ and (D) $14.06 \%$

mass and may lead to a false determination of the TP content. The intensity of the color on the reaction of phenolic compounds with the Folin-Ciocalteu reagent follows the traditional principle of the structure-activity relationships; i.e., the order of activity is proportional to the available hydroxyl groups present on the aromatic ring. ${ }^{13}$ Considering the molecular structure of the reference substances, pyrogallol contains the most hydroxyl groups in proportion to its molecular weight. Pyrogallol consists of only one aromatic ring with no groups replaced, which provides a three-dimensional structure that is less influenced by hydroxyl electronic interactions, such as the steric or resonance effect, which would reduce the availability of hydroxyl groups to reduce other compounds. Thus, pyrogallol has a higher specific absorptivity and is likely to be the best reference substance for the determination of TP to represent the reduction potential of the CE from $S$. terebinthifolius.

The analysis curves obtained for pyrogallol $(=0.1391 \mathrm{x}+0.0352$, $r=0.992)$ and $\mathrm{CE}(=0.0495 \mathrm{x}+0.0321, \mathrm{r}=0.996)$ showed that the method is linear over the concentrations examined and for the response obtained by the apparatus. This is observed from the linear correlation coefficient " $r$ " which has a value greater than 0.99 , as allowed by Anvisa 899/2003. The value of $\mathrm{F}$ found for the model was greater than the critical $\mathrm{F}$ value, and is the reverse for the lack of fit of adjustment. From the linear equation obtained, the limits of detection and quantitation were estimated as 0.2 and $2.0 \mu \mathrm{g} \mathrm{mL}^{-1}$, respectively.

With respect to precision, the variation coefficients of repeatability $(0.19 \%)$ and intermediate precision $(2.09 \%)$ showed that the results were within the limits allowed by the regulations $(\mathrm{RSD}<5 \%)$. There was no statistical difference in the intra-day and inter-day tests. Accuracy is considered the most important aspect of the analysis, indicating the effect of variations in a laboratory due to factors such as different days, analysts, or apparatus, thereby ensuring that the method is reproducible.

With respect to robustness, the absorbance measured after the
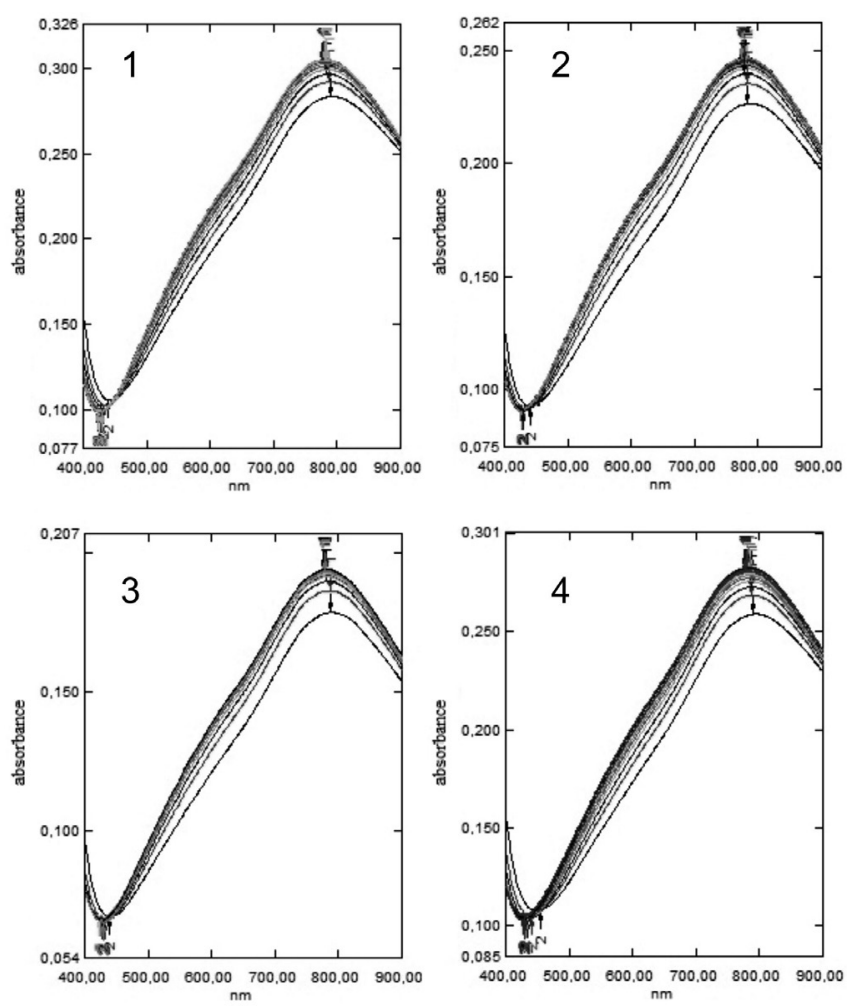

Figure 4. Absorption spectra (900-400 nm) for the reference substances in solutions containing $14.06 \% \mathrm{w} v^{-1}$ anhydrous sodium carbonate: (1) gallic acid, (2) tannic acid, (3) catechin, and (4) pyrogallol

incidence of natural light in the Folin-Ciocalteu reaction were 0.517 $\pm 0.021[4.24]$ and $0.557 \pm 0.008[1.54]$ without and with protection from light, respectively. The values found for the samples exposed to light were statistically different $(p<0.05)$ from those prepared with protection from light. So, there was a tendency for the proposed conditions and validated by method (protection from light).

Accuracy is considered as the degree of agreement between the true result (as obtained from the calibration curve), and the findings from a test sample. One method to evaluate accuracy consists of adding a standard at three different concentrations. If the curves are parallel, we can affirm that the method is selective. The selectivity of the method for $\mathrm{CE}(\mathrm{y}=0.0487+0.0371, \mathrm{r}=0.997)$ was confirmed by superimposing the analytical curves. The sample recovery was used to determine the accuracy, and we obtained a variation from 92.42 to $94.45 \%$, showing that the method is accurate for the complex matrix.

Bueno et al. ${ }^{11}$ optimized a technique for the assay of a hydroalcoholic PT extract of Caesalpinia peltophoroides Benth., and arrived at the following parameters: pyrogallol as the reference substance, use of anhydrous sodium carbonate at a concentration of $10.75 \% \mathrm{w} \mathrm{v}^{-1}$, 10 min time for the stabilization of the reaction, and $760 \mathrm{~nm}$ as the wavelength for reading. Lonni et al. ${ }^{14}$ reported that the use of quaternary mixtures with approximately equal portions of water, methanol, acetone, and ethanol for extraction from the bark of Trichilia catigua A. Juss. (Meliaceae) resulted in higher yields of crude extract, total polyphenol content, and antioxidant activity. On the other hand, Nepomucena et al. ${ }^{15}$ showed that the CE obtained from Pequi pulp after extraction with the ternary mixture of hexane, acetone and ethanol contained the maximum percentage of oil.

\section{CONCLUSION}

This study indicated that use of ternary mixtures with approximately equal portions of water, ethanol and acetone to extract phenols 
from the bark of Schinus terebinthifolius Raddi (Anacardiaceae) resulted in higher yields of the crude extract, total polyphenol content, and antioxidant capacity. CEs with values of antioxidant capacity less than 6.0 were obtained with a binary mixture of water: ethanol $\left(2: 8, \mathrm{v} \mathrm{v}^{-1}\right)$, water:acetone, and water:ethanol, in addition to that from pure ethanol. This study evaluated the extraction efficiency of different compositions of solvents on the bark of S. terebinthifolius. The determination of total polyphenols in CE of S. terebinthifolius showed satisfactory results with acceptable minimum requirements as stipulated by RE 899/2003, thereby ensuring the validity of the method. This methodology proved to be applicable in routine laboratory use for quality control.

\section{ACKNOWLEDGMENTS}

The authors are grateful for financial support from CAPES, FINEP, CNPq, INCT_if, and Fundação Araucária. Technical assistance provided by A. Arantes and C. R. Novello is gratefully acknowledged. Thanks are due to Dr. Janet W. Reid, JWR Associates, Trumansburg, New York, for English revision.

\section{REFERENCES}

1. Soares, P. K.; Bruns, R. E.; Scarminio, I. S.; J. Sep. Sci. 2009, 32, 644.

2. Souza, E. B. R.; Silva, R. R.; Afonso, S.; Sacrminio, I. S.; J. Sep. Sci. 2009, 32, 4176.

3. Garcia-Salas, P.; Morales-Soto, A.; Segura-Carretero, A.; FernándezGutiérrez, A.; Molecules 2010, 15, 8813.
4. Carvalho, M. G.; Freire F. D.; Raffin, F. N.; Aragão, C. F. S.; Moura, T. F. A. L.; Chromatographia 2009, 69, 249.

5. Lorenzi, H. Árvores Brasileiras: manual de identificação e cultivo de plantas arbóreas nativas do Brasil, $1^{\text {th }}$ ed., Plantarum: Nova Odessa, 1992.

6. Silva-Corazza, P. E. R.; Lopes, G. C.; DiCiaula, M. C.; Lima, M. M. S.; Mello, J. C. P.; Acta Farm. Bonaer. 2010, 29, 830.

7. Cicco, N.; Lanorte, M. T.; Paraggio, M.; Viggiano, M.; V. Lattanzio, V.; Microchem. J. 2009, 91,107.

8. Amarowicz, R.; Pegg, R. B.; Rahimi-Moghaddam, P.; Barl, B.; Weil, J.A.; Food Chem. 2004, 84, 551.

9. European Pharmacopoeia, $6^{\text {th }}$ ed, Strasbourg: Council of Europe, 2008.

10. BRAZIL. Ministry of Health National Health Surveillance Agency, laws, decrees. Resolution (RE) no. 899 of May 29, 2003. Mandates the publication of the "Guide to validation of analytical and bioanalytical methods", Brasília, 2003.

11. Bueno, F. G.; Marchareth, M. A. D.; Panizzon, G. P.; Lopes, G. C.; Mello, J. C. P.; Quim. Nova 2012, 35, 822.

12. Blainski, A.; Lopes, G. C.; Mello, J. C. P.; Molecules 2013, 18, 6852.

13. Singleton, V. L.; Orthofer, R.; Lamuela-Raventos, R.M.; Methods Enzymol. 1999, 299, 152; Nenadis, N.; Lazaridou, O.; Tsimidou, M. Z.; J. Agric. Food Chem. 2007, 55, 5452.

14. Lonni, A. S. G.; Longhini, R.; Lopes, G. C.; Mello, J. C. P.; Scarminio, I. S.; Anal. Chim. Acta 2012, 719, 57.

15. Nepomucena, T. M.; Silva, A. M.; Cirillo, M. A.; Quim. Nova 2013, 1, 36. 